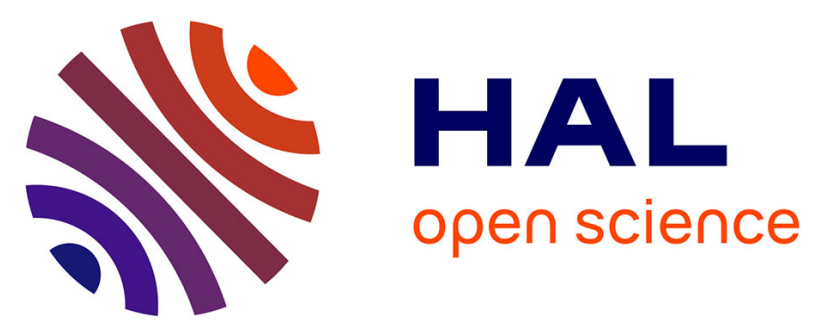

\title{
A Generic Knowledge-based Model for Commercial Offers : Towards a Unified Model to Configure Products, Services and PSS During Calls for Tenders
}

Delphine Guillon, Rania Ayachi, Élise Vareilles, Michel Aldanondo, Eric

Villeneuve, Andrés F. Barco, Christophe Merlo

\section{To cite this version:}

Delphine Guillon, Rania Ayachi, Élise Vareilles, Michel Aldanondo, Eric Villeneuve, et al.. A Generic Knowledge-based Model for Commercial Offers: Towards a Unified Model to Configure Products, Services and PSS During Calls for Tenders. IEEM 2019 - IEEE International Conference on Industrial Engineering and Engineering Management, Dec 2019, Macao, China. 5 p., 10.1109/IEEM44572.2019.8978790 . hal-02444003

\section{HAL Id: hal-02444003 \\ https://imt-mines-albi.hal.science/hal-02444003}

Submitted on 7 Feb 2020

HAL is a multi-disciplinary open access archive for the deposit and dissemination of scientific research documents, whether they are published or not. The documents may come from teaching and research institutions in France or abroad, or from public or private research centers.
L'archive ouverte pluridisciplinaire HAL, est destinée au dépôt et à la diffusion de documents scientifiques de niveau recherche, publiés ou non, émanant des établissements d'enseignement et de recherche français ou étrangers, des laboratoires publics ou privés. 


\title{
A Generic Knowledge-based Model for Commercial Offers: Towards a Unified Model to Configure Products, Services and PSS During Calls for Tenders
}

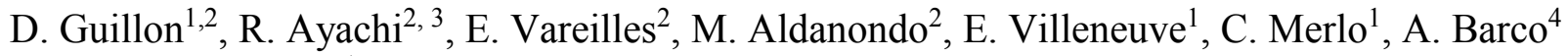 \\ ${ }^{1}$ University of Bordeaux, ESTIA Institute of Technology, France \\ ${ }^{2}$ Toulouse University, IMT Mines Albi, France \\ ${ }^{3}$ Toulouse University, ENI Tarbes, France \\ ${ }^{4}$ Universidad Santiago de Cali, Colombia \\ (elise.vareilles@mines-albi.fr)
}

\begin{abstract}
Today, consumption patterns are changing: firstly, customers (private and industrial ones) want more and more products and services that can be personalized to their needs, and secondly, they are more and more willing to pay for usage of a product rather than ownership. Companies have therefore to adapt their catalog of solutions by putting on the market customizable and suitable solutions going from products to services, including all their possible combinations. The aim of this article is to propose a generic knowledge-based model, dedicated to commercial offers configuration, which can cope with all the diversity of solutions a company can deliver. Up to our knowledge, even if some works on product, service and product-service system exist, none is generic enough to support such commercial offer configuration while bidding. In this paper, after a brief state-of-the-art, the need of a generic model is set up. Then, a unified model is proposed and illustrated on use-cases coming from industrial situations.
\end{abstract}

Keywords - Configuration, Knowledge-based model, Customer-supplier Relationship, Commercial Offer Definition

\section{INTRODUCTION}

Current market trends evolve in at least two important ways: firstly, from standard products and services to customized ones, and secondly, from the purchase of goods to their rental. To adapt to these new ways of consumption, companies have to put on the market a catalog of customizable solutions, ranging from product to service and including their combinations, also named Product-Service System or PSS [1]. These customizable solutions rely on predefined artefacts (components, subassemblies, services and modules), that can only be combined in specific ways.

Therefore, the definition of a commercial offer has to change: it must take into account both a technical solution (what the company sells to its customers, i.e. product and/or service) and its delivery process (how the company produces and delivers it). In the rest of the paper, regardless of the customizable solution (product or service) and the business model (B2C or B2B) [2], we consider that a commercial offer is composed of these two intertwined parts. Both of them rely on predefined artefacts and activities which can only be combined and integrated in a specific way. In view of these assumptions, it seems logical to consider the problem of commercial offer definition as a concurrent configuration problem [3], [4], [5]. To our knowledge, although some works exist on product configuration, service configuration and concurrent product-process configuration, none of the solutions are generic enough to support product, service and product-service configuration at the same time when defining commercial offers. Consequently, the aim of this article is to propose a unified knowledge-based model, dedicated to commercial offers configuration (technical solution and delivery process), which is able to cope with the whole range and variety of solutions a company can deliver.

The paper is organized as follows. In section 2, a brief state-of-the-art on concurrent configuration models is conducted to highlight the lack of generic model. In section 3 , the building blocks of the knowledge-based model are laid down and architectured in a unified model. A focus is made on the technical solution to present a new way of combining products and services in the same offer. In section 4, the unified model is instantiated on an industrial case to highlight the strengths of our proposal. Some conclusion and future research conclude our paper.

\section{STATE-OF-THE-ART}

As we consider that a commercial offer is composed of two intertwined parts (a technical solution and a delivery process), which must be configured with respect to their requirements, constraints and relations, thus, the configuration problem of a commercial offer is similar to a concurrent configuration problem.

First, let's have a look at the concurrent productprocess configuration problem. In such a problem, many authors [6], [3], [7], [4] agree that the product can be considered as a set of physical or tangible artefacts (commonly called sub-assemblies or components) and its delivery process as a set of activities or operations. With respect to the customers' needs, the generic model of the product and the generic model of the process, the concurrent product-process configuration is achieved by selecting components in component families (such as an engine reference), by choosing values for descriptive attributes (such as the power of a given engine), by selecting the set of relevant activities composing the process and for each one of these, choosing resources in resource families (such as a small machine in a machine 
list), along with a quantity. Of course, not all combinations of components, attribute values, resources and quantities are allowed, and for that reason, all these authors agree on the fact that a concurrent productprocess configuration problem can be considered and formalized as a constraint satisfaction problem or CSP [8], [9], [10].

Now, let's have a look at the service and PSS configuration. There is no clear definition of a service in the literature: a service can be seen as a process [11], [12], or a performance [13], [14], [15]. But all the authors agree on the point that a service is intangible, can be broken down into artefacts, called modules [16] or service components [17], and is difficult to separate from its delivery process. In addition, one can notice that more and more products are associated with services under the name of Product-Service Systems, also called PSS [18], as for example: installation, training or maintenance. Three categories of PSS, divided in eight types, have been defined [19], going from Product-oriented Service to Result-oriented Service. Given these elements and an ontology-based approach to represent configuration knowledge, [17] has proposed a generic model architecture for PES in Product-oriented Service.

As common features between products, services and PSS, we can say that:

- the technical solution of a commercial offer, whether dealing with a product, a service or a PSS, always requires an architecture based on predefined artefacts, which can be indifferently tangible or intangible,

- the delivery process of a commercial offer has to be taken into account on its own, to complete the cost of the commercial offer and better estimate its due-date.

Even if some works have already considered concurrent product-process configurations and service or PSS configurations by proposing generic models and tools to support their configuration, none of them is generic enough to cover the wide spectrum of commercial offers, or to differentiate the technical solution from its delivery process. To fill this gap, we propose a new generic way to define technical solutions by the use of $\underline{\mathrm{P} \vee \mathrm{SS}}$, which is integrated in a unified generic model for commercial offer, topic of section 3 .

\section{UNIFIED GENERIC MODEL}

As previously mentioned, companies now need to put on the market a wide range of customizable technical solutions, ranging from products to services, with all their combinations, known as a PSS. The literature review conducted on product, service and PSS configuration has highlighted the lack of a generic model capable of combining all artefacts (components, sub-assemblies, services, modules and activities) into a single commercial offer model, while considering explicitly the technical solution and the delivery process. This section is therefore dedicated to proposing and defining these artefact combinations, which we have called $\underline{\mathrm{P} \vee \mathrm{SS}}$, and of the generic model that can support its configuration.

\section{A. PVSS Definition}

The brief literature review has shown that the term PSS is not wide enough to encompass technical solutions with $100 \%$ of tangible artefacts (corresponding to products composed of components and sub-assemblies) or, indeed, $100 \%$ of intangible artefacts (corresponding to services composed of modules). PSS only allows products and services to be associated together but not decomposed one by the other.

At the contrary, $\mathrm{P} \vee \mathrm{SS}$ allow any artefact to be decomposed into tangible and/or intangible artefacts. The artefacts are simply tagged as tangible or intangible depending on their nature. With such a generic model, the difference between products, services and PSS no longer exists. It corresponds to the degree of tangibility of an artefact. The technical solution is therefore broken down into artefacts, which can themselves be broken down into other artefacts, regardless of their tangible or intangible nature (components, sub-assemblies, services or

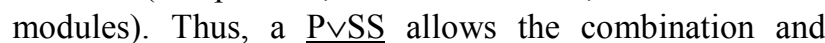
decomposition of all types of artefacts (components, subassemblies, services and modules) in a single commercial offer.

\section{B. Commercial Offer Unified Model}

Based on $\mathrm{P} \vee \mathrm{SS}$, a unified configuration model for commercial offers has to be formalized. This model must integrate the specificities of the commercial offers, distinguishing between the technical solution (what the company sells to its customers) and the delivery process (how the company produces and delivers it).

The proposed model is inspired by the work of [17], who has proposed configuring PES, using three subontologies: service (including the process), product and customer sub-ontologies. We propose completing and extending this model by the following information, as illustrated in Fig. 1:

(1) the key performance indicators which allow the characterization of commercial offers with relevant indicators and their comparison,

(2) the context in which the offer is taking place, corresponding to the state of the market, the customer's profile, the future state of the company in case of success and the customer's requirements (both from a technical point of view and from the point of view of the process),

(3) the architecture of the technical solution, corresponding to a structured list of artefacts or $\underline{\mathrm{P} \vee S S}$, 
(4) the definition of the delivery process, corresponding to the list of activities and resources involved.

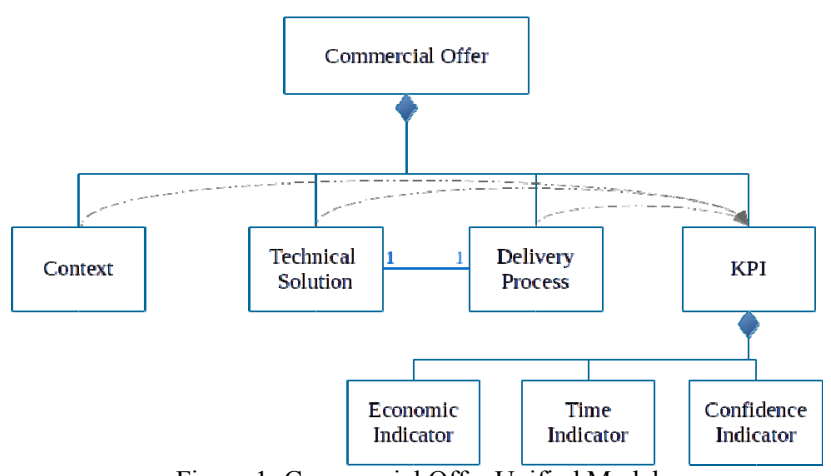

Figure 1: Commercial Offer Unified Model

Let's know focus on each of the four items composing a commercial offer.

Key performance indicators, or KPI, allow the comparison of several commercial offers, defined in the same context, which differ by their technical solution and / or delivery process. We consider as relevant KPI:

- economic indicator, taking into account both technical solution cost and delivery process cost, to estimate the cost and to price the commercial offer,

- time indicator, taking into account the duration of activities, in order to better estimate the due date,

- confidence indicator, taking into account the company's trust in its ability to provide the technical solution under the specified conditions (quality, price and due date) [20].

The context in which the offer is taking place has a strong impact on the way a company is designing its commercial offers, both on the technical solution and on the delivery process. For this reason it is important to characterize the context with relevant information dedicated to:

- The current state of the market. For instance, some questions have to be answered, such as "Are there potential competitors?", "Is it a market penetration strategy or an emerging market?", "Is it a private or a public market?",

- The customer's profile: Some questions about the potential client need to be addressed, such as "Is it a new or a regular customer?", "Is it a strategic customer?", "Are there any prices negotiated with this customer?", "Have there been any problems with this customer in the past?",

- The future state of the company in case of success: Some questions about the ability of the company to manufacture and deliver the technical solution in good conditions need to be answered, such as "What will the status of the order book be if we win the deal?", "Will my human and material resources be available on D-
Day?", "Will the workshop be able to handle the workload of this business?",

- The customer requirements: The needs, requirements or specifications must be carefully analyzed to customize the solution that best suits the stakeholders. Customer requirements are considered non-negotiable and must be understood appropriately. In the same way than [17], we consider that customer requirements can impact a function of the technical solution, a component, a service, an economic indicator or a time indicator

As customers increasingly want to personalize what they buy, regardless of whether it is a product, a service or a PSS, companies need to define solutions which are configurable and able to mix tangible and intangible artefacts in the same architecture. Customer requirements are therefore turned into a technical solution, by the selection of the relevant artefacts composing it. The

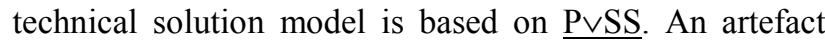
can be decomposed into other artefacts, and each artefact can be either tangible or intangible with regard to the concept it represents. The tangibility of any artefact relies on its association with a particular concept of the artefact ontology, in the same way as described in [17]. As previously stated, the technical solution is closely linked to the delivery process and vice versa, and has a direct impact on the economic indicator. Following the work of [18], any artefact can be associated with a delivery process. This association is supported by the use of an artefact ontology coupled with a CSP [19].

A sale process can be split into two main phases: (1) the definition of the commercial offer or pre-sale phase in which the commercial offer is designed and proposed to the customer [20] and the delivery process or post-sale phase which exists if and only if the commercial offer has been accepted. To be more precise, the definition of the commercial offer or pre-sale phase starts after the analysis of the business opportunity. It consists in the definition of the technical solution and the delivery process (composing a commercial offer) and stops when the commercial offer has been proposed to a customer. The delivery process or post-sale phase starts when the customer has accepted the commercial offer. It can be decomposed into two main sub-processes depending on

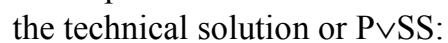

- the first sub-process is dedicated to the design, manufacturing and delivery of the technical solution, which can also be named preparation sub-process. This sub-process is carried out within the company and requires limited interaction with the customer, except to finalize the needs and requirements if needed,

- while the second one corresponds to the use or operation of the technical solution by the customer. It can also be called the operating sub- 
process. This sub-process is performed on the customer's premises with a strong customer involvement. The operating sub-process of a delivery process can therefore be rather long if the technical solution contains an artefact with long-term contract, such as a warranty extension or a 10 -year leasing service.

The delivery process stops when its last activity is carried out. This can be any type of activity of the preparation sub-process or operating sub-process. The delivery process needs to be carefully configured, so to be as accurate as possible on the delivery date, on the cost of the delivery process and on the risks taken by the company of not being able to deliver what has been sold to the customer in term of quality, price or due-date.

\section{ILLUSTRATIVE EXAMPLE}

In this section, we illustrate the generic model on an example. This simple but realistic example highlights the diversity that companies face when defining a commercial offer and show that our proposal can handle them. In this example, we show firstly the interest of mixing tangible and intangible artefacts in the same technical solution and secondly, the different shapes that the delivery process can have, depending on the customer's requirements.

Let's take as example a diagnosis and heavy maintenance on a CNC cutting machine. In such a case, the customer requirements could be the following:

- "Needs for a quote and diagnosis before maintenance of a CNC cutting machine"

- "Price less than $2.5 \mathrm{~K} \$$ for the diagnosis"

- "If needed, change all defective parts"

In this case, the technical solution is built on tangible artefacts, which are the spare parts needed to the $\mathrm{CNC}$ cutting machine, and on intangible artefacts corresponding to the diagnoses, maintenance, report and debriefing with the supervisor.

The delivery process includes the following activities:

- For the definition of the commercial offer: a diagnosis preparation activity, a spare parts picking activity, a report writing activity,

- For the delivery process: Diagnosis on site activity, maintenance on site activity, debrief with the supervisor activity.

All these tasks are intertwined as shown if Fig. 2.

Where a heavy maintenance is required, the cumulative price of all the components can be very expensive or the price of one particular part can be very costly. For example, the CNC cutting engine blocks can cost several thousand dollars each. Therefore, we can consider that the main cost allocation involves the tangible artefacts of the technical solution which makes the delivery process cost lower than the cost of the technical solution.

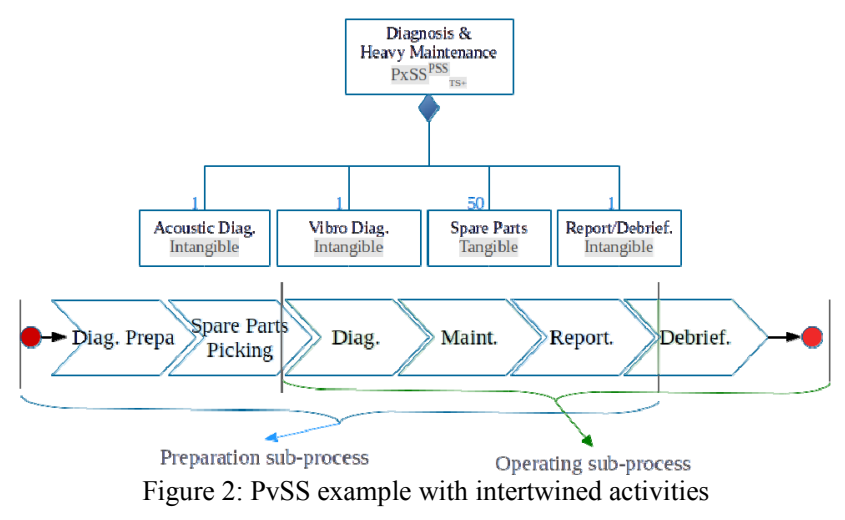

V. CONCLUSION AND FUTURE RESEARCH

Customers' needs and habits have rapidly evolved in recent decades and these changes have led them to completely change their consumption pattern. Now, it seems almost unthinkable to buy a standard product or service when it can be personalized to one's own needs. Furthermore, customers increasingly feel they have no need to buy and own products; instead, they prefer to pay for instant use of the product when needed. Companies have to adapt their catalog to these new trends by proposing customizable solutions, wide enough to cover products, services and all their combinations.

In this article, an innovative generic model has been proposed to help companies define their commercial offers in such a context. As we have seen, a commercial offer is composed of a technical solution (what the company sells) and a delivery process (how the company produces and delivers what has been sold). The proposed generic model derives its originality from the concept of $\underline{\mathrm{P} \vee \mathrm{SS}}$, for the technical solution. $\underline{\mathrm{P} \vee \mathrm{SS}}$ for Product $O R$ Service Systems allows the combination of different types of artefacts (components, sub-assemblies, services and modules) in a unique technical solution architecture. Each artefact, regardless of its tangible or intangible nature, can be decomposed recursively into other artefacts until the technical solution has been defined.

Inspired by the work of[17], a commercial offer is characterized by (1) a context in which the offer is taking place, (2) a technical solution defined using an ontology of artefacts, (3) a delivery process defined through an ontology of activities and finally (4) a set of key performance indicators, which includes economic, time and confidence indicators. In the commercial offer generic model, a clear distinction between intangible artefacts (services and modules) and the delivery process is made.

Our next objective is to implement the generic model in a decision support system or DSS, dedicated to defining 
commercial offers. The DSS has already been specified within a French project named OPERA2, which involves three universities as well as four companies in the secondary and tertiary sectors. It is currently in its development phase. When the DSS is ready, we need to validate it on industrial examples to test the relevance of the commercial offer generic model and the $\mathrm{P} \vee \mathrm{SS}$, in order to determine its usability and scalability in real situations.

\section{ACKNOWLEDGMENT}

We would like to thank all the industrial partners of the ANR Project OPERA for their involvement in the project.

\section{REFERENCES}

[1] O. Mont, "Clarifying the concept of product-service system" in Journal of Cleaner Production, 2002, vol. (10), pp. 237-245.

[2] C. Forza and S. Fabrizio, "Managing for variety in the order acquisition and fulfillment process: The contribution of product configuration systems. "), in International Journal of Production Economics, 2002, vol 76 (1), pp. 87-98.

[3] K. Schierholt, "Process configuration: combining the principles of product configuration and process planning." In Artificial Intelligence for Engineering Design, Analysis and Manufacturing, 2001, vol 15 (5), pp. 411-424.

[4] L. Zhang, E. Vareilles and M. Aldanondo, "Generic bill of functions, materials, and operations for SAP2 configuration." in International Journal of Production Research, 2013, vol 51 (2), pp. 465-478.

[5] P. Pitiot, M. Aldanondo and E. Vareilles, "Concurrent product configuration and process planning: Some optimization experimental results." in Computers in Industry, 2014, vol. 65 (4), pp. 610-621.

[6] S. Mittal and F. Frayman, "Towards a Generic Model of Configuraton Tasks." In IJCAI, 1989, Vol. 89, pp. 13951401.

[7] M. Aldanondo and E. Vareilles, "Configuration for mass customization: how to extend product configuration towards requirements and process configuration." $J$. Intelligent Manufacturing, 2008, vol 19 (5), pp. 521-535.

[8] U. Montanari, "Networks of constraints: Fundamental properties and applications to picture processing." Information Sciences 7 (Supplement C), 1974, pp. 95132.

[9] A. Felfernig, L. Hotz, C. Bagley and J. Tiihonen, "Knowledge-Based Con_guration: From Research to Business Cases. », 2014.

[10] R. Bartak, "Constraint Programming: In Pursuit of the Holy Grail." In Proceedings of the Week of Doctoral Students (WDS), 1999

[11] C. Grönroos, "Service management and marketing: customer management in service competition », 2000, John Wiley \& Sons.

[12] P. Carlborg and D. Kindström, "Service process modularization and modular strategies." Journal of Business \& Industrial Marketing, 2014, vol. 29 (4), pp. 313-323.
[13] C. Lovelock and E. Gummesson, "Whither Services Marketing?", Journal of Service Research, 2004, vol. 7 (1), pp. 20-41.

[14] A. Parasuraman, V. A. Zeithaml and L.L. Berry, "A Conceptual Model of Service Quality and Its Implications for Future Research." Journal of Marketing, 1985, vol 49 (4), pp. 41-50.

[15] V. A.. Zeithaml , A. Parasuraman, and L.L. Berry. "Problems and strategies in services marketing.", 1985 The Journal of Marketing, vol. 49 (2), pp. 33-46.

[16] M. Böttcher and S. Klingner. "Providing a method for composing modular B2B services." 2011, Journal of Business \& Industrial Marketing, vol. 26 (5), pp. 320331.

[17] J.L. Shen and Y. Sun, "Configuration of product extension services in servitisation using an ontology-based approach.", 2012, International Journal of Production Research, vol 50 (22):, pp. 6469-6488

[18] O. Mont, "Clarifying the concept of product-service system." 2002, Journal of Cleaner Production, vol. 10, pp. 237-245.

[19] A. Tukker, "Eight Types of Product Service Systems.", 2004, Business Strategy and the Environment, vol. 13:, pp. 246-260.

[20] A. Sylla, E. Vareilles, E. Coudert, K. Kirytopoulos, M. Aldanondo and L. Geneste, "Readiness, feasibility and confidence: how to help bidders to better develop and assess their offers." 2017, International Journal of Production Research, vol. 55 (23), pp. 7204-7222.

[18] E. Vareilles, T. Coudert, M.Aaldanondo, L. Geneste and J. Abeille, "System Design and Project Planning: model and rules to manage their interactions." 2015, Integrated Computer-Aided Engineering .

[19] J. Abeille, T. Coudert, E. Vareilles, L. Geneste, M. Aldanondo and T. Roux, "Formalization of an Integrated System/Project Design Framework: First Models and Processes." 2010, In Complex Systems Design \& Management, edited by Marc Aiguier, Francis Bretaudeau, and Daniel Krob, Berlin, Heidelberg, $207\{217$. Springer Berlin Heidelberg.

[20] R. Chalal and A.R. Ghomari, 2008 "An Approach for a Bidding Process Knowledge Capitalization." 2008, In world academy of science, Engineering and technology, Vol. 13. 